\title{
Uterine Artery Embolisation In Symptomatic Uterine Fibroid
}

\author{
Dr.Princey Rajakumari ${ }^{1}$, Dr.Banupriya ${ }^{2}$ \\ ${ }^{1}$ (Assistant professor, Department of OBG, Coimbatore Medical College Hospital, Coimbatore, India) \\ ${ }^{2}$ (Assistant professor, Department of OBG, Coimbatore Medical College Hospital, Coimbatore, India)
}

\begin{abstract}
Fibroid is the commonest benign tumour of uterus in reproductive age women. It causes symptoms like menorrhagia, dysmenorrhoea, pressure effects, infertility etc. impairing the women's day today activity. Uterine artery embolism is an emerging tecniqunic which is a non invasive procedure with short hospitalisation and early recovery. It preserves uterus and also improves the symptoms. This study is a prospective interventional trial which is done to find the effectiveness of the procedure in terms of improvement in symptoms like menorrhagia, dysmenorrhoea and pressure symptoms. This study also analyses the technical difficulties encountered in the procedure, complications during and after the procedure. 30 eligible patients are subjected to UAE after initial evaluation. From this study we have found that Uterine Artery Embolisation for the patients having symptomatic uterine fibroid is an effective and safe alternate treatment with significant reduction in patient's symptoms and good patient's satisfaction. It has less failure rates in short term follow up. Single femoral puncture technique can be used to embolise both uterine arteries successfully in most of the patients.. This procedure is safe and has good patient's tolerance, short recovery time, quick and sustained symptomatic improvement. Careful selection of cases and proper counselling before embolisation can bring maximum success to the procedure.
\end{abstract}

Keywords - Fibroids, uterine artery embolisation, uterine fibroid embolistion, seldingers technique, menorrhagia, dysmenorrhoea

\section{Introduction}

Fibroid (also called uterine leiomyoma, myoma, leiofibromyoma, fibroleiomyoma and fibroma) is a benign tumour that originates from the smooth muscles of myometrium and the accompanying connective tissue of the uterus. Fibroids are the most common benign tumour in females and typically found during the middle and later reproductive years seen in $40-50 \%$ of women older than 35 years [1]. It is estimated to occur in $40 \%$ of menstruating women older than 50 years. Symptoms caused by uterine fibroids are frequent indication for hysterectomy. Fibroids are often multiple. Most patients with uterine fibroids are asymptomatic [2].

Most common presenting symptoms of fibroids are Abnormal uterine bleeding,dysmenorrhoea,pelvic pain possibly resulting from intramural degeneration, torsion of pedunculated fibroid or uterine contractions.Pelvic pressure and abdominal distension in case of large fibroid which may manifest as genitourinary dysfunction like increased urinary frequency, acute urinary retention,flank pain resulting from urethral compression and hydronephrosis. Infertility is caused by distortion of uterine anatomy. Rarely it may also cause lower extremity oedema, constipation, or intestinal obstruction.

According to the location, fibroids are called as Intramural fibroids, Subserosal fibroid (sometimes pedunculated), Sub mucosal fibroids and cervical fibroids. Intra mural fibroids are the most common type causing menorrhagia and dysmenorrhoea. These intra mural fibroids can be treated with uterine fibroid embolisation.

Various medical and surgical therapies are used to treat fibroids. Medical therapy includes hypo estrogenic drugs, which causes temporary reduction in size and relief of symptoms. Surgical treatment includes myomectomy or hysterectomy. Uterine fibroid is one of the leading causes for hysterectomy today in India and worldwide.

Transcatheter embolisation of the uterine arteries for symptomatic fibroids has become an increasingly important alternative treatment. It is highly effective and well tolerated by most patients. Most notably, uterine artery embolisation is minimally invasive associated with a short recovery period and is uterine sparing. Estimated 13,000-14,000 UFE procedures are performed annually in U.S. (as of 2004). In India uterine fibroid embolization is less popular and done in very few centres. This study is to determine the benefits and effectiveness of uterine artery embolization in symptomatic uterine fibroid and use the same as an alternate primary treatment for uterine fibroids. 
II. Aim

The aim of this study is to analyse the effectiveness, technique, complication and outcome after uterine artery embolisation in patients with symptomatic uterine fibroid.

\section{Uterine Fibroid Embolisation}

Embolization[3] is defined as the "therapeutic introduction of various substances into the circulation to occlude selective vessels, either to arrest or prevent haemorrhage, to devitalize a structure, tumour or organ."

\subsection{PROCEDURE}

Uterine fibroid embolisation is a minimally invasive outpatient procedure done under local anaesthesia with or without sedation. Selective catheterisation is done by seldinger technique using multipurpose $4 \mathrm{~F}$ or $5 \mathrm{~F}$ cobra catheter. Unilateral or bilateral catheterisation made to embolise both uterine arteries. The uterine artery is more easily accessed from the contra lateral femoral artery. Angiography and embolisation is performed using an 800ma conventional angiographic unit (SIEMENS). A bilateral catheterisation is also used to reduce the time taken for the procedure [4]. A flush aortogram is taken initially by placing catheter at L1 level to detect any aberrant supply to the uterus. Catheter passed to the contra lateral common iliac artery, internal iliac then anterior branch of internal iliac artery and to the uterine artery. Catheter is advanced under fluoroscopic guidance. Catheter is placed in the horizontal part of uterine artery beyond the origin of descending cervical branch. After confirming the position of the catheter by injecting contrast material, embolisation done using PVA particles or Gel form.

Similar procedure is repeated on the other side. After embolisation vascularity to the fibroid is reduced and standing column of contrast seen is in uterine artery. A tight plaster is applied over the punctured site. Procedure takes $1 / 2-1 \mathrm{hr}$ to complete. Patient is observed for $24 \mathrm{hrs}$.

\subsection{HOW UFE ACTS:}

Uterine fibroid embolisation acts mainly by occluding the capillaries and arterioles since fibroid supplied by end arteries without much anastamosis. This causes shrinkage of the tumour and stops appearance of new fibroids as per long term follow up studies. Blood supply to normal myometrium is not much compromised because of extensive anastamotic network.

\subsection{EMBOLIC MATERIAL:}

Gelatin sponge and poly vinyl alcohol are the commonly used embolic materials. Gel foam, a gelatine sponge material, which is cut into small pieces that are injected into an artery and float downstream until they can go no further. After a period ranging from a few days to two weeks, the material dissolves. Particulate agents, including poly vinyl alcohol (PVA) and gelatin-impregnated acrylic polymer spheres, which are suspended in liquid is also used instead of Gel form. These agents occlude vessels permanently. They are commonly used in the treatment of uterine fibroid.

\subsection{END POINT OF EMBOLISATION:}

- Occlusion of the identifiable vessels supplying the fibroids with preservation of as much of the normal uterine flow.

* Evidence of a standing column of contrast in the uterine artery and reflux towards the uterine artery origin or into the internal iliac artery.

* Cessation of flow in the ascending uterine artery with residual flow in the lower uterine segment supplying the normal myometrium.

\section{Materials And Methods}

In this study 32 patients with fibroid uterus having at least one of the following symptoms are selected

\subsection{INCLUSION CRITERIA}

1. Women with symptomatic fibroid (menstrual disturbances or pressure symptoms due to size or pain) who want to retain their uterus and avoid surgery.

2. Solitary or multiple intramural fibroids of less than $7 \mathrm{~cm}$.

3. Parous women who completed family and age less than 40 yrs.

4. Women who give consent to undergo uterine artery embolisation and participate in the study.

\subsection{EXCLUSION CRITERIA}

1. Women with asymptomatic fibroid.

2. Infertile women or parous women who want to conserve uterus for future pregnancy.

3. Fibroids of more than $7 \mathrm{~cm}$ or with degenerative changes or hypo vascularity on Doppler study.

4. Sub mucous or pedunculated Subserosal fibroid. 
5. Previous history of anaphylaxis to contrast.

6. Systemic illness like HIV, HbsAg +ve, abnormal renal profile, Coagulation disorders.

\section{Methodology}

A detailed history was taken to know the severity of symptoms. Menorrhagia was assessed by Pictorial Blood Loss Assessment Chart (Hallberg et al.)[5]. Patients were asked to keep a detailed menstrual calendar denoting the number of pads used, soakage of each pad, duration of flow and passage of clots.

Dysmenorrhoea was assessed by Visual analogue scale [6] using a 10-cm line represented the continuum. The participants were asked to rate the degree of pain by making a mark on the line.

Pressure symptoms were assessed by the presence or the absence of lower abdominal heaviness, increased frequency of micturation or constipation.

\subsection{PROCEDURE:}

\subsubsection{PRE ANAESTHETICS}

- Inj Dexamethasone 8mg I.V Stat

- Inj. Pheniramine Maleate I amp I.M Stat

- Inj. Atropine Iamp I.V.Stat

Given half ah hour before the procedure.

\subsubsection{ANTI BIOTIC PROPHYLAXIS:}

- Inj Ampicillin 1gm I.V (ATD)

5.1.3. ANESTHESIA/ SEDATION:

- Inj Tramadol 1 amp IM

5.1.4. PATIENT POSITION: Supine

5.1.5. APPROACH: Percutaneous transfemoral approach

5.2. POST PROCEDURE EVENTS:

Patients were observed in high dependence ward for $6 \mathrm{hrs}$ then at least $48 \mathrm{hrs}$ in the routine wards. All the patients were carefully observed for any complications like groin haematoma /retroperitoneal haematoma. Vitals were checked. Patients were kept nil per oral for 4 hours. They were advised bed rest for 6 hours and then ambulated. Patients were discharged after 48-72 hrs.

All of them were advised to maintain menstrual calendar in detail regarding the duration, number of pads soiled, clots passed and associated pain after discharge.

\subsection{FOLLOW UP:}

At the end of $3^{\text {rd }}$ month patients were called and enquired about their menstruation, dysmenorrhoea and pressure symptom. USG Pelvis performed to know the size \& volume of fibroid. Similarly at $6^{\text {th }}$ month patients were called, enquired and a review USG was taken.

\section{Analysis and results}

32 patients with uterine fibroid who were fit according to the inclusion criteria were taken up for this study. Embolisation was done after adequate counselling and getting informed written consent. Successful embolisation was done in 30 patients. Therefore data was analysed for 30 patients.

\subsection{AGE}

In this study women below the age of $40 \mathrm{yrs}$ are selected for UFE. Age distribution of the study population is given below.

Mean age of the study population was 32.43 yrs and range was 26-39yrs.

\begin{tabular}{|l|l|l|}
\hline \multicolumn{2}{|c|}{ Table: 1. "Age distribution of subjects" } \\
\hline Age Group & Frequency & $\%$ \\
\hline $26-30$ & 10 & 33.33 \\
\hline $31-35$ & 17 & 56.67 \\
\hline $36-40$ & 03 & 10.00 \\
\hline Total & 30 & 100.00 \\
\hline
\end{tabular}

\subsection{INDICATION FOR EMBOLISATION:}

Among 30 patients $23(76.67 \%)$ patients preferred uterine artery embolisation than Hysterectomy. Out of 7 patients $5(16.67 \%$ ) were severely anaemic because of menorrhagia so preferred uterine artery embolisation for anaesthetic risks. One patient had undergone two laparotomies previously hence preferred uterine artery 
embolisation for her menorrhagia. One patient was morbidly obese. She preferred uterine artery embolisation considering the risk of thrombo embolism, wound infection etc...

\begin{tabular}{|l|l|l|}
\hline \multicolumn{2}{|c|}{ Table:2 "Indications- Distribution of subjects" } \\
\hline Indications & Frequency (No. of subjects) & $\%$ \\
\hline Opted & 23 & 76.67 \\
\hline Anaemia & 05 & 16.67 \\
\hline Obesity & 01 & 03.33 \\
\hline Previous surgery & 01 & 03.33 \\
\hline Total subjects & 30 & 100.00 \\
\hline
\end{tabular}

\subsection{PRESENTING COMPLAINTS:}

Among menorrhagia, dysmenorrhoea and pressure symptoms, menorrhagia was the most common presenting symptom. It was present in all the patients. Dysmenorrhoea was present in $23(76.66 \%)$ of the subjects. Pressure symptoms was present in $6(20 \%)$ of the patients.

\begin{tabular}{|l|l|l|}
\hline \multicolumn{3}{|c|}{ Table:3 "Symptoms- Distribution of subjects" } \\
\hline Symptoms & Frequency & $\%$ \\
\hline Menorrhagia & 30 & 100.00 \\
\hline Dysmenorrhoea & 23 & 76.66 \\
\hline Pressure symptom & 06 & 20.00 \\
\hline
\end{tabular}

\subsection{MENORRHAGIA:}

Menorrhagia was present in all of the subjects. Menorrhagia was assessed by Pictorial Blood Loss Assessment[PBLA] Chart. As per Higham et al[7] who analysed pictorial blood loss, PBAC scoring of $>100$ is diagnostic of menorrhagia, that is blood loss of $>80 \mathrm{ml}$ with specificity and sensitivity of $>80$. All patient had Pictorial Blood Loss Assessment scoring of $>100$. Average blood loss scoring in this study was 202.66 and ranges from 100-315.Pictorial Blood Loss Assessment scoring distribution of the patients before treatment is given below.

\begin{tabular}{|l|l|l|}
\hline \multicolumn{2}{|c|}{ Table 4: "Menorrhagia distribution" } \\
\hline PBLA Scoring & Samples & $\%$ \\
\hline $100-150$ & 7 & 23.33 \\
\hline $151-200$ & 7 & 23.33 \\
\hline $201-250$ & 11 & 36.66 \\
\hline$>250$ & 05 & 16.66 \\
\hline Total & 30 & 100.00 \\
\hline
\end{tabular}

\subsection{DYSMENORRHOEA}

Dysmenorrhoea was assessed by Visual Analogue Scale [6]. Before embolisation mild dysmenorrhoea was present in 2 patients, moderate dysmenorrhoea was present in 10 patients and severe dysmenorrhoea in 11 patients.

\begin{tabular}{|l|l|l|}
\hline \multicolumn{3}{|c|}{ Table: 5. "Dysmenorrhoea Before Treatment" } \\
\hline Grading & No of Subjects & $\%$ \\
\hline No dysmenorrhoea & 07 & 23.33 \\
\hline Mild dysmenorrhoea & 02 & 06.67 \\
\hline Moderate dysmenorrhoea & 10 & 33.33 \\
\hline Severe dysmenorrhoea & 11 & 36.67 \\
\hline Total & 30 & 100.00 \\
\hline
\end{tabular}




\subsection{PRESSURE SYMPTOMS:}

Pressure symptoms present in 6 of the patients (20\%).4 patients had increased frequency of micturation and 2 patients had feeling of lower abdominal heaviness.

\begin{tabular}{|l|l|l|}
\hline \multicolumn{2}{|c|}{ Table:6"Distribution Of Pressure Symptom" } \\
\hline Pressure symptoms & No of subjects & $\%$ \\
\hline No pressure symptoms & 24 & 80.00 \\
\hline Frequency of micturation & 04 & 13.33 \\
\hline Lower abdominal heaviness & 02 & 06.67 \\
\hline Total & 30 & 100.00 \\
\hline
\end{tabular}

\subsection{SIZE AND VOLUME:}

Fibroid volumes are determined with the formula $A \times B \times C \times 0.523$, where $A, B$, and $C$ are the dimensions in the three orientations in ultrasound assuming the fibroid has an ellipsoid shape [8]. Volume of fibroid in this study ranges from $40.01-276.14 \mathrm{cu} \mathrm{cm}$. Average volume of fibroid before treatment was $104 \mathrm{cu}$ $\mathrm{cm}$. Largest size of fibroid in this study was $10 \mathrm{x} 8 \times 6.6 \mathrm{~cm}$. Volume distribution of fibroid is given below.

\begin{tabular}{|l|l|l|}
\hline \multicolumn{2}{|c|}{ Table: 7. " Volume Distribution Of Fibroids " } \\
\hline Volume of fibroid (cu cm) & No of subjects & $\%$ \\
\hline$<50$ & 05 & 16.67 \\
\hline $50-100$ & 11 & 36.67 \\
\hline $100-150$ & 08 & 26.66 \\
\hline $150-200$ & 05 & 16.67 \\
\hline$>200$ & 01 & 03.33 \\
\hline Total & 30 & 100.00 \\
\hline
\end{tabular}

\subsection{TECHNICAL DIFFICULTIES:}

Technical difficulties was seen in $3(9.99 \%)$ of the patients. Catheterisation of uterine artery was difficult because of vasospasm in 3 patients. Unilateral embolisation was done in one patient and other two patients catheterisation could not be done on both sides and the procedure abandoned. For another patient unilateral embolisation done because of sub intimal dissection on one side.

\begin{tabular}{|l|l|l|}
\hline \multicolumn{2}{|c|}{ Table: 8. Technical difficulties } \\
\hline Technical difficulties & No of subjects & $\%$ \\
\hline Bilateral embolisation & 28 & 87.5 \\
\hline Unilateral embolisation & 2 & 6.25 \\
\hline Unsuccessful catheterisation & 2 & 6.25 \\
\hline Total & 32 & \\
\hline
\end{tabular}

\subsection{COMPLICATIONS:}

Complication rate in this study was $3.12 \%$ (serious complication). One case of sub-intimal dissection was seen. For her embolisation was successfully done in the contra lateral side. Then on catheterising the ipsilateral side sub-intimal dissection occurred and further procedure abandoned. Inj heparin $5000 \mathrm{u}$ sc BD was started. No long term sequela was seen in that patient. No other major complication occurred during the procedure. As explained earlier 3 patients had vasospasm.

\begin{tabular}{|l|l|l|}
\hline \multicolumn{3}{|c|}{ Table: 9. Complications During Procedure } \\
\hline Category complication & No. Of Subjects & $\%$ \\
\hline Vasospasm & 03 & 09.38 \\
\hline Subintimal dissection & 01 & 03.12 \\
\hline No Complication & 28 & 87.50 \\
\hline Total & 32 & 100.00 \\
\hline
\end{tabular}




\subsection{POST PROCEDURE EVENTS:}

90\% of the patients complained of pain in the lower abdominal and low back ache.20\% had vomiting and $10 \%$ had fever. All these complications were self limiting. One patient had post embolisation syndrome (PES) and was re-admitted after a week.

\begin{tabular}{|l|l|l|}
\hline \multicolumn{3}{|c|}{ Table: 10. Post Procedural Events } \\
\hline Complication & No Of Patients & $\%$ \\
\hline Pain & 27 & 90 \\
\hline Vomiting & 6 & 20 \\
\hline Fever & 3 & 9.99 \\
\hline PES & 1 & 3.33 \\
\hline
\end{tabular}

\subsection{DURATION OF HOSPITAL STAY}

Average duration of hospital stay for the patients who underwent UFE was 2.6 days. Range of duration of hospital stay was 3 to 7 days. One patient who had sub intimal dissection stayed for 7 days. All other patients discharged on $2^{\text {nd }}$ or $3^{\text {rd }}$ day.

\begin{tabular}{|l|l|l|}
\hline \multicolumn{3}{|c|}{ Table: 11. Distribution Of Duration of Hospital Stay } \\
\hline Duration & No Of Patients & $\%$ \\
\hline 2 Days & 16 & 53.34 \\
\hline 3days & 13 & 43.33 \\
\hline$>=4$ Days & 1 & 3.33 \\
\hline
\end{tabular}

\subsection{FOLLOW UP ANALYSIS:}

At the end of $3^{\text {rd }}$ month all the 30 patients came for follow up. Their menstrual calendar was analysed, symptoms enquired and clinical examination was done. USG was done for all patients to assess the size and volume of the fibroid. Only 12 patients completed $6^{\text {th }}$ month follow up. Others yet to come for follow up at 6 months.

\subsubsection{MENORRHAGIA ON FOLLOW UP}

At 3 months menstrual blood loss was significantly reduced. $83 \%$ had moderate to significant improvement in their mean blood loss. Pictorial blood loss scoring reduction ranges from 10 to $95 \%$ at the $3^{\text {rd }}$ month and 45 to $76 \%$ at the $6^{\text {th }}$ month. By paired ' $t$ ' test reduction in blood loss at 3 months was highly significant with $p<0.00001$.

\begin{tabular}{|l|l|l|}
\hline \multicolumn{3}{|c|}{ Table: 12. Distribution of Improvement in menorrhagia After 3 Months } \\
\hline Improvement in the blood loss & No. of Subjects & $\%$ \\
\hline Worsening <0 & 0 & 0 \\
\hline Remaining the same 0-10\% & 0 & 0 \\
\hline Mild-10-30\% & 05 & 16.67 \\
\hline Moderate-30-50\% & 16 & 53.33 \\
\hline Good >=50\% & 09 & 30.00 \\
\hline Total Subjects & 30 & 100.00 \\
\hline
\end{tabular}

At 6 months menorrhagia markedly reduced. All the patient had PBLA scoring of $<100$ that is no menorrhagia after 6 months.

\subsubsection{DYSMENORRHOEA ON FOLLOW UP:}

Among 23 patients presented with dysmenorrhoea significant improvement in dysmenorrhoea seen in 87\% of patients. Only 2 of the patient's dysmenorrhoea remained the same at 3 months. At the end of 6 months none of the patients had severe dysmenorrhoea. 


\begin{tabular}{|l|l|l|}
\hline \multicolumn{2}{|c|}{ Table: 13. Improvement in dysmenorrhoea after 3 months } \\
\hline & Before Procedure & After 3 Months \\
\hline Nil & 7 & 7 \\
\hline Mild (1-4) & 2 & 14 \\
\hline Moderate (5-7) & 10 & 9 \\
\hline Severe (>7) & 11 & 0 \\
\hline & 30 & 30 \\
\hline
\end{tabular}

\subsubsection{VOLUME CHANGES:}

In this study, mean reduction in the volume at the $3^{\text {rd }}$ month was $29.91 \%$ and at the $6^{\text {th }}$ month was $46.66 \%$. Range of volume reduction varied from 9 to $50 \%$ at 3 months and $27-65 \%$ at 6 months. Paired "t" test was used to analyse the volume change after 3 months. It was highly significant with p value of $<0.0001$ at 3 months. In this study moderate to marked reduction in dominant fibroid volume was seen in $40 \%$ of the patients at $3^{\text {rd }}$ month and $91 \%$ at $6^{\text {th }}$ month

\begin{tabular}{|l|l|l|}
\hline \multicolumn{2}{|c|}{ Table: 14. Volume Reduction of Fibroid After 3 Months } \\
\hline & No. Of Subjects & $\%$ \\
\hline Worsening & 0 & 0 \\
\hline Remaining The Same 0-10 & 01 & 03.33 \\
\hline Mild-10-30 & 17 & 56.67 \\
\hline Moderate-30-50 & 12 & 40.00 \\
\hline Total Subjects & 30 & 100.00 \\
\hline
\end{tabular}

\begin{tabular}{|l|l|l|}
\hline \multicolumn{3}{|c|}{ Table: 15. Reduction In Fibroid Volume After 6 Months } \\
\hline & No. Of Subjects & $\%$ \\
\hline Worsening & 0 & 0 \\
\hline Remaining The Same 0-10 & 0 & 0 \\
\hline Mild-10-30 & 1 & 08.33 \\
\hline Moderate-30-50 & 6 & 50.00 \\
\hline Good >=50 & 5 & 41.67 \\
\hline Total Subjects & 12 & 100.00 \\
\hline
\end{tabular}

\subsubsection{VOLUME REDUCTION GELFOAM VS PVA:}

For embolisation we have used gel foam for 15 patients and poly vinyl alcohol for 15 patients. On analysing the volume reduction at 3 months, mean volume reduction for gel foam and poly vinyl alcohol was $27.86 \%$ and $31.95 \%$ respectively. By unpaired test value $p$ value was $1.15(>0.5)$ which was insignificant.

6.12.5. PRESSURE SYMPTOMS:

In this study 6 of them had pressure symptoms. 4 had increased frequency of micturation. 2 had lower abdominal heaviness. Pressure symptoms disappeared at 3 months for all of them.

\begin{tabular}{|l|l|l|}
\hline \multicolumn{2}{|c|}{ Table:16" Pressure Symptoms After Treatment" } \\
\hline Pressure symptoms & Before treatment & 3 months after treatment \\
\hline Frequency of micturation & 04 & 0 \\
\hline Lower abdominal heaviness & 02 & 0 \\
\hline Total & 6 & nil \\
\hline
\end{tabular}

No long term complication seen in this study.

\section{Discussion}

Fibroid uterus is one of the common benign gynaecological disorders encountered in the reproductive age women. Although various medical treatments available they are ineffective because of their side effects and temporary relief. Hence many young women forced to undergo hysterectomy at an early age. Uterine artery embolisation is a minimally invasive alternative primary treatment of fibroids with preservation of uterus. This 
study was done to know the effectiveness, tolerability and complication of this procedure which can be used as primary procedure.

Samples were collected according to the inclusion and exclusion criteria. They were assessed in detail and contra-indications were ruled out. Totally 32 samples were taken for this study. For 2 patients embolisation could not be done because of vasospasm. Successful embolisation was done for 30 patients. Hence we have analysed data for 30 patients.

Out of $30,23(76.67 \%)$ of them preferred UFE to hysterectomy. In the remaining samples, 5 (16.67) had severe anaemia, one had under gone previous surgery and one was morbidly obese thus preferred UAE to prevent surgical and other complications.

Majority of the patients opted to undergo Uterine Artery Embolisation because of the following benefits:

- Short duration of hospital stay.

- Simple procedure.

- Safe compared to hysterectomy as per previous studies

- Satisfactory results of the previous studies.

- Avoid surgical complications (Anaemic patients, obese patients and patients undergone previous surgery - anaesthetic risk, infection and injury to vital structure because of adhesion)

Mean Age of the study population was 32.43 years which ranges from 26-39. The study population below 40 years were selected because, as age increases associated problems like carcinoma of endometrium and ovarian pathologies increases which mandates surgical management. Above the age of 40 years $3 \%$ of myomas are associated with endometrial carcinoma ${ }^{\mathbf{4 5}}$. Also in post menopausal women and peri menopausal women the fibroid size regresses after menopause because of its estrogens dependent nature.

Menorrhagia was present in all the patients which were assessed by Pictorial Blood Loss Assessment Chart. As per Higham et al [7] who analysed pictorial blood loss, PBAC scoring of $>100$ is diagnostic of menorrhagia, that is blood loss of $>80 \mathrm{ml}$ with specificity and sensitivity of $>80 \%$. All patient in this study had Pictorial Blood Loss Assessment scoring of $>100$. Average blood loss scoring in this study was 202.66 and ranges from 100-315.

Dysmenorrhoea was present in 23(76.66\%) of the subjects and was assessed by Visual Analogue Scale. Before embolisation mild dysmenorrhoea was present in $2(7 \%)$ patients, moderate dysmenorrhoea was present in $10(33.3 \%)$ patients and severe dysmenorrhoea in 11(37\%) patients.

In this study Pressure Symptoms was present in only 6(20\%) of the selected population. This may be because of the restriction of size of fibroid <7c.m.4 (13.33\%) had increased frequency of micturation and $2(6.67 \%)$ had feeling of lower abdominal heaviness.

In this study, average volume of fibroid before embolisation is $104 \mathrm{cu} . \mathrm{cm}$. Largest fibroid in the study population was $10 \mathrm{x} 8 \times 6.2 \mathrm{~cm} \&$ volume $274.14 \mathrm{cu} . \mathrm{cm}$. Previously said large fibroids are associated with more complication. In our series we have not encountered any additional complications in larger fibroids. This correlates with the recent study by Albret J Smeetsetal[9] shows complications were not increased and clinical response is also good.

In this study unilateral femoral puncture technique was used in all patients. Bilateral femoral puncture with cross-over technique which was used initially for UAE was faster and needs shorter screening time than unilateral catheterization. However, with experience, ipsi-lateral catheterization of uterine artery can be carried out quickly and is widely practiced today. We have used unilateral femoral puncture technique, not encountered any complication related to femoral puncture and catheterisation. This correlated with the study, Pelage JP, Soyer P, et al. [10], found unilateral femoral puncture was safe and with lesser incidence of complications such as haematoma and dissection of arteries.

Pre procedural antibiotics and analgesics were given to all patients. None of the patients required any further sedatives or anaesthesia during the procedure.

Successful bilateral embolisation was done for $28(87.5 \%)$ of the patients. Technical difficulties was seen in $4(12.5 \%)$ of the patients. Catheterisation of uterine artery could not be done because of vasospasm. Unilateral embolisation was done in two patient and other two patients catheterisation could not be done on both sides and the procedure abandoned. This is comparable with Brunereau et al.[11] Who reported 84\% successful catheterisation. Pelage et al [10], reported successful catheterisation in $92 \%$ of cases.

Serious complication rates in this study were 3.33\% which is little higher compared to other studies. This can be attributed to smaller sample size. We have encountered one sub intimal dissection alone and no other serious complications like vascular perforation or allergy to contrast media noted. Spice et al [12] who published the largest series found an overall $8.5 \%$ short-term complication rate and a $1.25 \%$ serious complication rate. Infective complications have been noted in other studies which were not seen in this study. Vashisht et al. [13] reported one death due to septicaemia following UAE leading to multi organ failure. Walker and Pelage [14] have reported three (1\%) infective complications leading to hysterectomy. Hence, preexisting infection must be excluded and proper antibiotic cover must be given before UAE. Expulsion of 
fibroids vaginally after UAE has been reported in $2.5 \%$ of patients by Goodwin et al. [15] . In this study, no such incidence was recorded.

Duration of the procedure varied from 45 minutes to 75 minutes. The average duration of the procedure was 65 minutes. This is comparable with results of previous researches. The mean total procedure time as reported by other investigators has been $78.4 \mathrm{~min}$ for bilateral approach [16] and 44.29[17] and 61[18] min for unilateral approach. Fluoroscopic exposure time was $45 \mathrm{~min}$, which is more compared with reported times of 25.3[16], 13.69[17] and 18.9[18] min. In this study intermittent fluoroscopy was used to reduce the exposure.

Post Procedural Events: Majority of the patients (90\%) complained of pain in the lower abdominal and low back ache. Pain subsided with NSAIDs. Rarely narcotic analgesics needed. $20 \%$ had vomiting and $10 \%$ had fever. All these complications were self limiting. Patients observed for 48 hours 72 hours and then discharged. None of the patients developed hematoma or any other serious complication in immediate post procedure period. One patient had post embolisation syndrome (PES) and was re-admitted after a week.

Patients were advised to take bed rest for $6 \mathrm{hrs}$, then minimal activity up to $24 \mathrm{hrs}$, after that were ambulated well and observed in hospital. Patients without complications were discharged on the $2^{\text {nd }}$ or $3^{\text {rd }}$ day.

Mean Duration of Hospitalisation was 2.6 days in this study. Most of the patients were discharged on $2^{\text {nd }}$ or $3^{\text {rd }}$ day. Only one patient who had sub-intimal dissection was discharged on $7^{\text {th }}$ day. She was treated with heparin 5000u sc BD. MRI Scan and Doppler flow was assessed and found to be normal. Another patient was readmitted with the complaints of fever and myalgia. She was treated with antibiotics \& antipyretics and was investigated for infections which were negative. Patient recovered after 2 days and was discharged. Pain and vomiting was seen in most of the patients. Pain was confined to lower abdomen and back region and was reduced with NSAIDS. Duration of hospital stay is comparable with Brunereau L, et al. [11] who reported 2.3 days. In some hospitals the patients discharged after an overnight stay. This can also suggested in future, as there was no complication seen after $24 \mathrm{hrs}$.

Follow up: Patients are called at the end of 3 months and 6 months. Menorrhagia was assessed by Pictorial Blood Loss Assessment Chart and dysmenorrhoea by Visual analogue Scale.USG was done to know the size of fibroid.

In this study on the $3^{\text {rd }}$ month follow up, there was significant Improvement in Menorrhagia (83\% of patients) ( $p<0.00001$ highly significant). No patients had worsening of menorrhagia. At 6 months all (100\%) patients had PBLA scoring below 100 that is blood loss $<80 \mathrm{ml}$. It was comparable to the study reported by Ravina et al [19] (81\%) and Goodwin et al.[20] (81\%). Improvement in blood loss ranges from 10 to $95 \%$ at 3 months. At the $6^{\text {th }}$ month the improvement in menorrhagia ranges from 45 to $76 \%$.One $(3.33 \%)$ patient had Transient Amenorrhoea. She resumed her menstruation 4 months after the procedure. No cases of permanent amenorrhoea seen in this study.

Similarly there was significant Improvement in Dysmenorrhoea seen in $87 \%$ of patients. Only 2 of the patient's dysmenorrhoea remained the same at 3 months. At the end of $6^{\text {th }}$ month none of the patients had severe dysmenorrhoea. This results correlated with the findings of Mahmood et al. [21] from Stansford University who showed $74 \%$ had improvement in dysmenorrhoea.

Average Volume Reduction at the $3^{\text {rd }}$ month was $29.91 \%\left(p<0.0001\right.$ highly significant) and $6^{\text {th }}$ month was $44.66 \%$. Range of volume reduction varied from 9 to $50 \%$ at 3 months and $27-65 \%$ at 6 months. It comparable with that seen in the study by Spies et al.[22], who has reported $50 \%$ at $6^{\text {th }}$ month and $78 \%$ at $1^{\text {st }}$ year.

Gel foam Vs Poly Vinyl Alcohol as embolic agent: Among 30 patients in the study 15 of them were embolised with gel foam and remaining 15 was embolised with ploy vinyl alcohol particles of 350-500 $\mu \mathrm{m}$ size. On analysing the volume reduction, both was equally effective. This result is comparable with Katz et al [23] who studied the effectiveness of gelatin sponge pledgets versus polyvinyl alcohol for embolization. They concluded that materials are equally effective.

\section{Conclusion}

From this study we have found that Uterine Artery Embolisation for the patients having symptomatic uterine fibroid is an effective and safe alternate treatment with significant reduction in patient's symptoms and good patient's satisfaction. It has less failure rates in short term follow up. Although long term follow needed to confirm it. Single femoral puncture technique can be used to embolise both uterine arteries successfully in most of the patients. Both the embolizing agents (Gel foam \& PVA) are equally effective in relieving the symptoms. This procedure has good patient's tolerance, short recovery time, quick and sustained symptomatic improvement. As the previous studies do not support future fertility it should be used with caution in patients who want future conception. Careful selection of cases and proper counselling before embolisation can bring maximum success to the procedure. This procedure may reduce the need for invasive surgery in many patients. From this study we conclude that UFE is a minimally invasive, safe and effective treatment for properly selected patients with uterine fibroids. 


\section{REFERANCE}

[1]. Marshall LM ,Spiegeiman D,Barbieri et al. Variation in the incidence of uterine lieomyoma Camoung premenopausal woman by age and race . Obstet gynecol 1997;94:967-973

[2]. Day Baird D,Dunson DB ,Hill MC,et al. Incidence of lieomyoma: ultrasound evidence. Am J Obstet gynecol 2003:188:100-107

[3]. Robert I. White, MD, "Interventional Radiology: Reflections and Expectations", Radiology, 1987; 162: 593-600.

[4]. Pelage JP, Soyer P, Dref OL et al. Uterine arteries: bilateral catheterization with a single femoral approach and a single 5F catheter - Technical Note. Radiology 1999; 210: 573-75.

[5]. Hallberg L, Nilsson L. Determination of menstrual blood loss. Scand J Clin Lab Invest 1964; 16: $244-248$.

[6]. Wewers M.E. \& Lowe N.K. (1990) A critical review of visual analogue scales in the measurement of clinical phenomena. Research in Nursing and Health 13, 227 \pm 236 .

[7]. Higham, J. M., O'brien, P. M. S. and Shaw, R. W. (1990), Assessment of Menstrual Blood Loss Using a Pictorial Chart. Bog: An International Journal of Obstetrics \& Gynaecology, 97: 734-739.

[8]. PronG, Bennett J, Common A, Wall J, Asch M, Sniderman K. The Ontario Uterine Fibroid Embolization Trial. II. Uterine fibroid reduction and symptom relief after uterine artery embolization for fibroids. Fertil Steril 2003; 79: 120-127.

[9]. Albert J. Smeets, Robbert J. Nijenhuis, et al Uterine Artery Embolization in Patients with a Large Fibroid Burden: Long-Term Clinical and MR Follow-up. The Netherlands 15-12-2009.

[10]. Pelage JP, Soyer P, Dref OL et al. Uterine arteries: bilateral catheterization with a single femoral approach and a single 5F catheter - Technical Note. Radiology 1999; 210: 573-75.

[11]. Brunereau L, Herbreteau D, Gallas S et al. Uterine artery embolization in the primary treatment of uterine leiomyomas. AJR 2000; 175: 1267-72.

[12]. Spies JB, Spector A, Roth AR, Baker CM, Mauro L, Murphy-Skrynarz K. Complications after uterine artery embolization for leiomyomas. Obstet.Gynecol 2002; 100: 873-880.

[13]. Vashisht A, Studd JW, Corey AH et al. Fibroid embolisation: a technique not without significant complications. Br J Obstet Gynaecol.2000; 107: 1166-70.

[14]. Walker WJ, Pelage JP. Uterine artery embolisation for symptomatic fibroids: clinical results in 400 women with imaging follow up. Br J Obstet Gynaecol 2002; 109: 1262-72.

[15]. Goodwin SC, McLucas B, Lee M et al. Uterine artery embolisation for the treatment of uterine leiomyoma - midterm results. J Vasc.Interv Radiol 1999; 10: 1159-65.

[16]. Spies JB, Scialli AR, Jha RC, Imaoka I, Ascher SM, Fraga VM, Barth KH. Initial results from uterine fibroid embolization for symptomatic leiomyoma. Department of Radiology, Georgetown University Medical Centre, Washington, DC 20007-2197, USA J Vasc Interv Radiol. 1999 Oct;10(9):1145-7.

[17]. Ho SS, Cowan NC. Uterine artery embolisation for uterine fibroids using a 4F Rosch inferior mesenteric catheter. Eur Radiol 2005; 15: 1168-72.

[18]. PronG, Bennett J, Common A, Wall J, Asch M, Sniderman K. The Ontario Uterine Fibroid Embolization Trial. II. Uterine fibroid reduction and symptom relief after uterine artery embolization for fibroids. Fertil Steril 2003; 79: 120-127.

[19]. Ravina JH, Herbretean D, Ciraru-Vigneror N et al. Arterial embolisation to treat uterine myomata. Lancet 1995; 346: 671-72.

[20]. Scott Goodwin, M.D. Long-Term Efficacy of Uterine Fibroid Embolization Confirmed. Department of Radiological Sciences in the School of Medicine at the University of California, Irvine.

[21]. Mahmood K. Razavi, Gloria Hwang, et al. Abdominal Myomectomy versus Uterine Fibroid Embolization in the Treatment of Symptomatic Uterine Leiomyomas. Department of Vascular and Interventional Radiology \& Department of Gynaecology and Obstetrics, Stanford University Hospital, Stanford, October 30, 2002.

[22]. Spies JB, Scialli AR, Jha RC, Imaoka I, Ascher SM, Fraga VM, Barth KH. Initial results from uterine fibroid embolization for symptomatic leiomyoma. Department of Radiology, Georgetown University Medical Centre, Washington, DC 20007-2197, USA J Vasc Interv Radiol. 1999 Oct;10(9):1145-7.

[23]. Katz R, Mitty H, Stancato-Pasik A, et al: Comparison of uterine artery embolization for fibroids using gelatin sponge pledgets and polyvinyl alcohol. J Vasc Interv Radiol 9(suppl 1):184, 1998. 